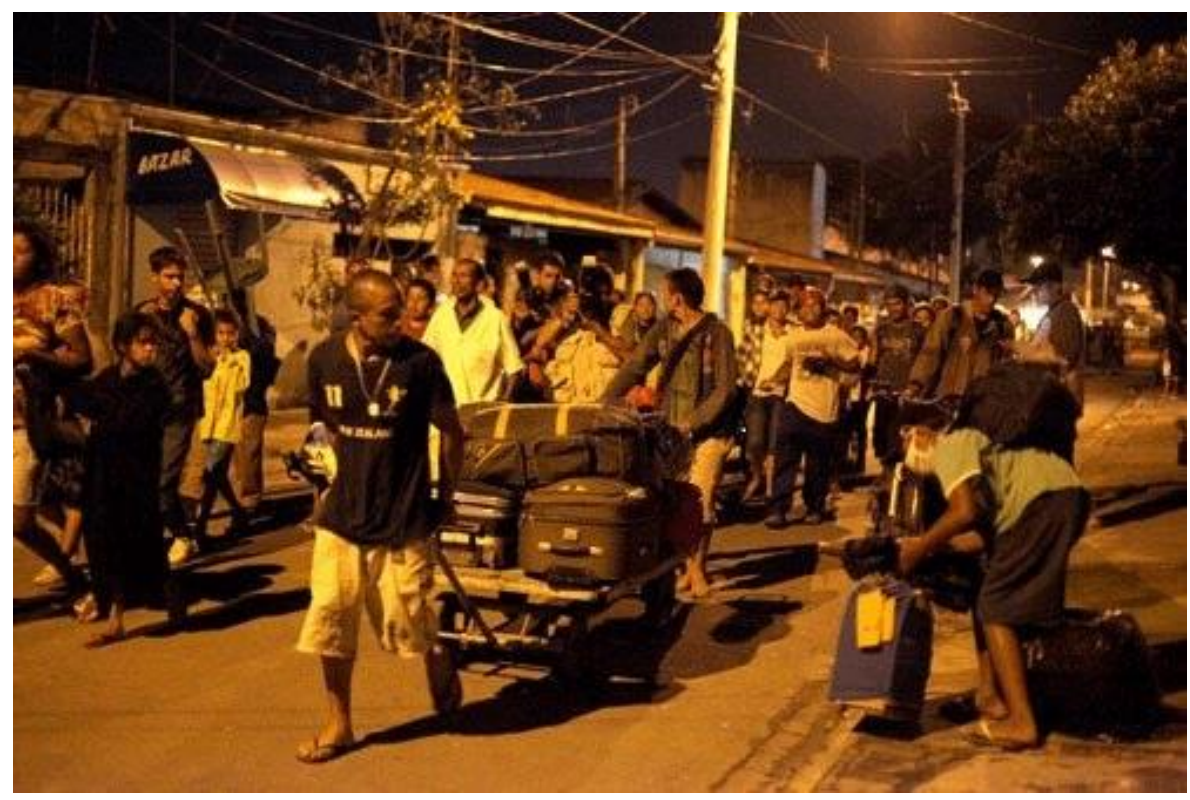

\title{
Havia uma Canudos no "Pinheirinho" em São José dos Campos: Sentidos da ação policial no espaço urbano.
}

War of Canudos relived in Pinheirinho: meanings of police action in urban space.

\section{Anderson de Carvalho Pereira*}

\section{Resumo:}

Uma das reportagens sobre a violenta ação policial ocorrida no bairro Pinheirinho em São José dos Campos, interior de São Paulo, no início de 2012, estabelece analogias com a derrocada do arraial de Canudos, ao fim do século XIX. Neste artigo, mostramos um lugar do imaginário sobre espaço urbano, a partir da análise de enunciados veiculados em manchetes bem como em formas narrativas acerca dessa ação policial ocorrida no bairro Pinheirinho. Por meio de uma análise discursiva, apontamos os mecanismos ideológicos por meio dos quais se sustentam evidências de sentidos sobre ação policial no espaço urbano. Assim, indicamos sentidos sobre espaço urbano em que a inquietação e a resistência confrontam a aparente resolução da problemática habitacional brasileira nas grandes cidades.

Palavras-chave: Canudos, planejamento urbano, cidade, discurso, São José dos Campos.

\section{Abstract:}

One of the news reports on the violent police action that took place in Pinheirinho, a quarter in the city of São José dos Campos, Brazil, in the beginning of 2012, pointed out the similarity of this action to the war of Canudos, which happened in the late $19^{\text {th }}$ century. In this paper, we aim at elucidating an imaginary about urban space through analysis of enunciations in newspaper titles and in reports on the police action that took place in Pinheirinho. Based on French Discourse Analysis, we pointed out the ideological mechanisms that support semantic evidences in reports on military actions in urban space. Therefore, meanings about public spaces in which social anxiety and resistance occur confront the apparent well-adjustment of habitation policies in Brazilian big cities.

Keywords: Canudos; urban space; city; discourse; São José dos Campos.

\footnotetext{
${ }^{*}$ Doutor em Psicologia pela USP, com estágio na Universidade de Paris XIII. Professor Adjunto do Departamento de Educação, Ciências Humanas e Linguagem da Universidade Estadual do Sudoeste da Bahia. Rodovia BR 415, Km 03, S/N. bairro: Morumbi. 45.700-000 - Itapetinga, BA - Brasil. email: apereira.uesb@gmail.com
} 


\title{
Introdução
}

No início de 2012, o bairro Pinheirinho localizado em São José dos Campos, interior de São Paulo, foi noticiado como palco de violenta ação policial que à primeira vista parece pura decorrência do cumprimento de mais um mandato judicial, mas que expõe um sintoma social que retorna no país e faz voltar à tona o debate sobre "habitação urbana".

Uma dessas notícias chama a atenção por conta do arranjo narrativo e pela formulação parafrástica. Leiamos:

\begin{abstract}
“Título - Pinheirinho: uma Canudos em São José dos Campos. Por Clovis Oliveira (09/02/2012). Um bairro de trabalhadores e gente pobre. Os terrenos são relativamente grandes. As ruas são largas. Existem serviços públicos e igrejas (A Canudos do final do Século XIX também tinha duas delas). Na verdade, Pinheirinho faz parte de São José dos Campos, perfeitamente integrado com os bairros vizinhos. Por que não reconhecer a comunidade de Pinheirinho e garantir uma melhor infraestrutura para aquele povo? Por que não redistribuir só um pouco da riqueza de São José dos Campos, uma das mais ricas cidades do Brasil?"1 (negritos no original; grifos nossos)
\end{abstract}

Além de diversos textos em blogs, jornais impressos, vários vídeos põem em cena um campo vasto de significações. Trata-se de um acontecimento cuja dispersão de sentidos em torno conclama um debate sobre a luta pela terra no Brasil, de caráter mais amplo, e concomitantemente a fluidez e as políticas de assepsia do espaço urbano.

Defendemos que uma das formas possíveis de apontar para algumas arbitrariedades envolvendo práticas sociais naturalizadas em nosso país, principalmente ligadas aos mandos e desmandos do avanço de interesses privativos nos espaços públicos em razão de uma avassaladora política do Capital neoliberal, é pela análise de sentidos envolvidos à ação policial, como no caso aqui analisado.

É por este caminho discursivo que apresentaremos alguns gestos interpretativos em torno desta questão que consolidam e engendram na opacidade da trama de sentidos uma tentativa de calar os conflitos, as contradições e contornar as problemáticas sociais em sua dimensão político-histórica por meio da política do contorno a essas contradições de que resultam os "consensos" que escondem desnivelamentos, mas que deixam escapar "um sujeito ardente" (PÊCHEUX, 1993, p.30).

\footnotetext{
${ }^{1}$ Retirado de http://cspconlutas.org.br/2012/02/pinheirinho-uma-canudos-em-sao-jose-doscampos-porclovis-oliveira/ acesso em: 3/5/2013;
} 


\section{Urbanidade e visibilidade: a consolidação de uma "Personalidade democrática" no espaço urbano}

Do ponto de vista da memória discursiva não é à toa que começamos pelo trecho em destaque, de cuja reflexão resulta o propósito maior expresso no título deste artigo. Wissenbach (1999) explica que o que ocorre em Canudos, ao final do século XIX no Brasil é um marco para situarmos a discussão sobre as cidades brasileiras da época e, acrescentamos, discussão esta atualizada nos dizeres acima.

O caráter da cidade imprevisível, em Canudos, ameaça as autoridades republicanas por meio de seus "fanáticos religiosos" e de seu afronte à ordem religiosa e estatal, cujas bases políticas, científicas e morais se encontravam no positivismo francês e no darwinismo social inglês inspiradores da República. Isto porque nas grandes cidades consolidadas já se consolidava uma roupagem de aglomerações étnicas por meio da detecção de quais aspectos de desordem citadina em cortiços, vilas, áreas consideradas insalubres são lidos pelas autoridades e setores dominantes como ameaça à organicidade da ordem pública (WISSENBACH, 1999).

Em meio a esses interesses da intelectualidade e da classe dominante em torno do início da República é que temos o marco da construção social da favela, a partir da derrocada dos cortiços e o acuo no "Morro da Favella" ou Morro da Providência, onde muitos ex-combatentes de Canudos se instalaram e clamaram pelo pagamento dos soldos devidos pelo governo da época (VALLADARES, 2000). Isto porque, explica Wissenbach (1999), a favela já havia sido uma designação para o morro onde as tropas do governo haviam se estabelecido e de onde se avistava o arraial de Canudos.

Wissenbach (1999, p.96) ainda lembra o papel dos cronistas dos jornais da época; são eles que: "observam que as primeiras habitações do morro da Providência foram sendo criadas a partir de acampamentos de ex-combatentes da Guerra de Canudos" sendo que "a eles se juntaram os sobreviventes de Canudos, centenas de mulheres e crianças trazidas para a capital federal".

Valladares (2000) explica que este morro tornou-se então marco de uma onda migratória dos pobres na cidade e lugar para onde se voltaram as atenções da vigilância sanitária e os empreendimentos de limpeza social das autoridades da época, marcando uma mentalidade dominante sobre a pobreza e a habitação urbana; além disso, a autora traça um percurso de como os relatos de jornalistas em geral e de Euclides da Cunha já teciam analogias entre topografias de terreno e principalmente um modus vivendis entre o arraial de Canudos e as favelas cariocas, numa política de ação social de seus 
moradores em que a apropriação de um território de "todos e de ninguém" subvertia a “ordem" imposta pelo Estado.

Partimos da retomada desta lacuna da memória discursiva que alinha e lineariza um lugar do imaginário no primeiro relato aqui destacado sobre o acontecimento marcado pela ação policial ocorrido no bairro "Pinheirinho" em São José dos Campos. É esta lacuna que nos orienta nesta perspectiva discursiva da escrita sobre o jogo de sentidos envolvidos aos relatos sobre o acontecimento.

Notamos que esta tentativa de homogeneização presente nos discursos fundadores (ORLANDI, 2001) sobre a favela e a habitação urbana popular em geral contrariam a pluralidade das populações ligadas a este modelo de habitação, o que é mostrado por Tatagiba et all (2012) ao analisarem o "movimento de moradia" do período recente da cidade de São Paulo-SP.

Ao empregarmos uma leitura rápida e dispersa sobre o corpus de que trata este artigo, percebemos a predominância de marcas verbais como: desocupar, ocupar, invadir, reivindicar, despejar, guerrear, reintegrar. Numa análise prévia e inicial, chama a atenção o referencial semântico ligado a conflito em todos esses usos verbais.

Alguns desses verbos (“ocupar, reivindicar e participar”) é ponto de partida para o artigo desses pesquisadores, que demonstram o modo articulado pelo qual os movimentos populares por moradia na capital paulista (idem), na linha da denúncia de que como aponta Valladares (2000) ainda permanecem atualmente ações governamentais higienistas que somente agravam segmentações discriminatórias no espaço urbano, uma vez que essas ações violentas não se separam da crença na necessidade de limpeza moral.

Tatagiba et all (2012) abordam que tem se acentuado na capital paulista problemas ligados à moradia por conta da intensificação da especulação imobiliária do grande Capital, abusos de intermediários, despejos sem aviso prévio. Disso decorre um "repertório de ações coletivas" usado para assegurar o direito à moradia digna em movimentos populares, cujas origens múltiplas aparecem principalmente no contexto de redemocratização do país com alcance internacional e apoio de setores de engajamento social da igreja católica, bem como atravessado por grupos que também militam em favor de temas transversais reconhecidos oficialmente pelos órgãos oficiais da administração pública. 
As invasões são apontadas como elemento positivo de coesão interna do grupo, mas alimentam insegurança pelo medo da violência (TARROW, 1997 apud TATAGIBA et all, 2012, p. 413). Citando:

O medo da repressão policial é um argumento mobilizado por 34\% dos que se posicionaram contra as ocupações. A criminalização dos movimentos sociais, ao lado da criminalização da pobreza, tem sido uma prática recorrente das administrações municipais que se sucederam desde 2005 (PSDB, DEM e PSD) da cidade de São Paulo, com reintegrações de posse violentas e repressões truculentas não só ao movimento de moradia, mas também ao movimento dos sem-teto, ao movimento estudantil e ao movimento dos moradores de rua. (grifo nosso)

Como se percebe na citação, há uma atualização da memória discursiva de fundo higienista, na medida em que as contradições sociais são interpretadas como desordem e a tomada de posição invariavelmente dos oprimidos como fato objetivo; esta objetivação das contradições sociais em que o sujeito é interpelado como criminoso, no caso, por conta da zona de sentido acerca da luta por moradia de que se apropria faz parte a nosso ver de um dos mecanismos ideológicos cuja eficácia se dissipa no cotidiano.

Orlandi (2011) discute essas questões ligadas à complexidade do espaço urbano e do "sentir-se em casa" clamando pela assertividade de nossa constituição simbólica, em que a ausência do Estado para transformar o espaço público em lugar de cuidado para o convívio entre concidadãos não pode deixar prevalecer a violência desmedida.

Isto ocorre porque se trata de um lugar aberto à interpretação. Do ponto de vista teórico, trata-se do embate do político (do âmbito do real) em seu modo de afetar o simbólico. Além disto, vale notar o domínio das formações imaginárias veiculadas em termos das projeções dos especialistas e de suas abstrações e representações quantitativas a favor do grande Capital. Disso decorre um emaranhado de sentidos sobre urbano, cidade e relações sociais; conforme a autora:

Tenho afirmado em meus trabalhos que a cidade tem sido confundida, ou melhor, que há uma sobreposição do urbano sobre a cidade. Isto quer dizer que a cidade é significada pelo urbano. Este, por sua vez, não representa a cidade em seu real, mas é justamente o imaginário pelo qual a cidade é tomada ou como espaço empírico, já preenchido, ou como um espaço abstrato, calculável, administrado por especialistas da gestão pública: com seus planos, projetos, políticas públicas etc. Nesse sentido, enquanto declinada pelo urbano, a cidade é já significada a priori, em nosso caso, pelos padrões capitalistas. Indo mais além, podemos mesmo dizer que o urbano se sobrepõe à cidade e esta é identificada com o social, isto é, as relações sociais são hoje, muito frequentemente, consideradas como o mesmo que relações urbanas (ORLANDI, 2011, p. 695). 
A atualização de um lugar para o sujeito, do ponto de vista da articulação entre o simbólico e o político pela qual se significam ações do citadino é marcada por um Estado que o individualiza; este entendimento passa pelas contribuições de Orlandi, que aponta nesse processo dinâmico da significação uma marca de tentativa do Capital em tentar estagnar o dinamismo das constantes interpretações, mas à qual se sobrepõe uma insistente significação de resistência da cidade (ORLANDI, 2011).

A partir disso temos uma organização dos "processos de individualização cuja marca do político é reger o poder conforme a discriminação de diferenças pelo valor desigual entre o melhor, o pior, o rico, o pobre, o superior, o inferior, o que tem a existência garantida e o que não deve existir, etc" (op.cit. p. 696). Conforme a mesma autora, é notória a avassaladora proposta de recortar o espaço urbano em condomínios, espaços herméticos em que "individualizam-se as respostas sociais aos problemas que são comuns a todos" (op.cit. 697).

Isto demonstra uma das formas de decorrência da especialização do lugar público e privado, de tal forma que o bairro antigo ou a vila são espaços de transição a serem reconhecidos no cotidiano como possibilidade de ratificação de hábitos consolidados na ida ao bar, padaria, etc (PROST, 2002).

Num modelo mais recente de urbanização, regida quase somente pelo grande capital especulativo por meio de projetos voltados aos interesses de uma privatização do espaço público, o poder público está aberto à privatização e não se atenta que para além do utilitarismo há funções sociais em jogo na delimitação desses espaços transitórios consolidados historicamente e com grande valor social e cultural.

Sendo assim, Prost (op.cit.) explica que as normas de convívio da liberdade burguesa para a qual movimentar-se também é tentar resguardar a privacidade, o que exige refugiar-se da vigilância dos olhares alheios, avançam em aliança aos imperativos higienistas que marcaram o início do século XX (cf. VALLADARES, op.cit.; TATAGIBA, op.cit.); isto porque tal assepsia evitaria o contato e o convívio acentuando-se os limites da propriedade privada e a distância das regras privadas na apropriação do espaço público, cada vez mais, imbuído de hábitos, por exemplo, como os do universo do trabalho.

Esta função dos papéis sociais é por nós entendida neste artigo no âmbito dos determinantes discursivos, dentre estes, o político (cf. ORLANDI, 2011) e que tem nesta discussão relação estreita com o debate sustentado por Haroche (2005) acerca da 
consolidação de uma Personalidade democrática no espaço urbano, por meio de uma remodelagem da deferência a outrem.

Até a consolidação da "personalidade democrática" definida por uma organicidade bem como harmonia entre a conduta e a deferência no espaço público, Haroche (2005) nos mostra a complexidade e dispersão de atitudes e modos de aparição pelos quais as democracias se consolidam. Dentre estes, temos a crença na liberdade como atributo individual e o distanciamento que implica o compromisso não tão explícito com o outro, sendo que esta deferência "pode depender da amabilidade, da urbanidade" que "comporta uma parte intrínseca e irredutível de atenção (autêntica ou aparente), que pode ser de difícil aplicação nas democracias" (HAROCHE, 2005, p.133).

$\mathrm{Na}$ seção a seguir, será este o fio da memória ao qual retornaremos ao movimentarmos a análise dos efeitos de sentido que se movimentam em torno das manchetes e das narrativas que colocam o bairro Pinheirinho na esfera dos acontecimentos do cotidiano recente acerca dos sentidos sobre a ação policial na designação de um lugar no imaginário sobre espaço urbano no Brasil.

\section{Domínio de memória e dispersão de sentidos: a constituição de um lugar no imaginário sobre a ação policial}

Para a análise do corpus nos orientamos principalmente pela noção de recorte como unidade de sentido em torno de uma questão (cf. ORLANDI, 1987, 1996) e de sequência discursiva apresentada por Serrani (1997).

Deste modo, a partir das diversas (re)leituras do corpus elegemos inicialmente quatro questões decorrentes do estranhamento de algumas marcas linguísticas indiciárias das seguintes questões, a saber: 1- uma oposição no uso da nomeação entre duas zonas de sentido em efeito de dominação e apagamento; 2- o efeito de sentido ligado ao caráter de "surpresa" ou "imprevisto" da ação policial; 3 - o uso disperso de verbos pelos quais o relato da ação policial no bairro Pinheirinho é linearizado pelo domínio de memória envolvido com a "luta pela terra" no Brasil. A partir desta formação do corpus são mostradas sequências discursivas (SDs), a partir das quais operam-se retornos à teoria e à formulação inicial da questão.

Uma primeira sequência discursiva é a seguir apresentada a partir da interpretação do estranhamento do uso do anonimato para se referir aos moradores do bairro Pinheirinho em oposição à nomeação clara e precisa dos diversos agentes 
policiais. Esta diferença de nomeação clara para o anonimato é visivelmente marcada pela diferença entre a zona de sentidos instalada com o uso do verbo "prender". Vejamos a SD1:

\begin{abstract}
Com a decisão do tribunal estadual, a expulsão da comunidade "Pinherinho" teve início no domingo (22) às 6 horas da manhã. Mais de 2 mil pessoas e guardas civis metropolitanos chegaram ao local com um aparato de guerra. Eles utilizaram carro blindado para abrir caminho, seguido da Tropa de Choque e da equipe da ROTA (tropa de elite de São Paulo). Dois helicópteros Águia também foram utilizados na operação. (...) A resistência do Pinheirinho durou até o dia seguinte, quando os últimos moradores foram retirados de suas casas. 30 pessoas foram presas durante a operação, entre elas vários dirigentes dos movimentos sociais (29/1/2012, retirado do site "autogestão.org", acesso em: 3/5/2013; grifos nossos)
\end{abstract}

Nesta SD, chama a atenção que a nomeação referente a uma parte específica do grupo de moradores (dirigentes dos movimentos sociais; grifo nosso) aparece apenas após o uso do verbo "prender"; instala-se uma zona de apagamento da memória discursiva. Isto porque, de um lado, nomeiam-se os "órgãos oficiais" (guardas civis metropolitanos; Tropa de Choque; equipe da ROTA (tropa de elite de São Paulo); Dois helicópteros Águia); de outro, a voz anônima dos dirigentes, cuja retroação se ancora na voz anônima dos moradores representados por estes, segue um processo discursivo em que o anonimato é oposto à nomeação dos órgãos oficiais.

Somado a isto, a nomeação que aparece com a modalização "tropa de elite de São Paulo" configura legitimidade à ação por conta da similaridade com as ações semelhantes nos morros cariocas e também pela possível deriva do sentido de "elite" para "classe sócio-econômica mais abastada".

$\mathrm{Na}$ análise de Courtine (2006, p. 78-79) sobre o discurso comunista endereçado aos cristãos, a referência à nomeação aparece como um "sinal irredutível de diversidade"; o autor completa: "a estrutura de uma classe referencial desse tipo explica a produção de efeitos do real por um sujeito".

Quer dizer, mesmo em se tratando de sentidos provisórios, temos um lugar de evidência para a "ação policial", inclusive pela aparente sinonímia com "operação" (deriva possível, pelo deslizamento metafórico de uma verticalidade que sustenta essa ação, num nível de transversalidade discursiva); provisórios porque o real não cessa de insistir sobre um resto, abertura esta ligada aos outros sentidos possíveis em deriva como acontecimento do discurso (PÊCHEUX, 1997).

Sem marcar de forma mais clara quem eram os agentes da resistência, no caso, os moradores, o relato segue com a designação "resistência do Pinheirinho", num 
processo de alienação ao sentido dominante que confere legitimidade à ação policial pela visibilidade dos nomes e siglas oficiais amparadas por uma "equipe", somando-se a isto o fato de que o trabalho em equipe mobiliza o sentido de cumprimento eficaz de um dever, o que em tempos de valorização do homem "gerencial", "manager" de si mesmo potencializa um efeito de sentido dominante.

A resistência de uma "voz anônima" (COURTINE, 1982) ou de um nome genérico em que não se discriminam "as pessoas" a que se refere é oposta à nomeação dos "órgãos oficiais", de modo que se tem a consolidação de um domínio de memória sobre a ação policial. Nas palavras de Courtine (2006, p. 79), aparece uma articulação conceitual e uma questão crucial que pode ser compartilhada no caso do corpus aqui analisado:

a função interdiscursiva como domínio de memória permite ao sujeito, portanto, o retorno e o reagrupamento de enunciados assim como o seu esquecimento ou apagamento. Primeiramente, isso deve conduzir-nos a interrogar as modalidades da constituição de séries de formulações no interdiscurso: como um espaço de repetições se inscreve em um conjunto desigualmente estratificado do discurso? (COURTINE, 2006, p. 79)

Adiante, temos que a marcação se especifica após o relato da prisão de pessoas, em "entre elas, vários dirigentes de movimentos sociais". Nota-se ainda o uso da nomeação "dirigentes" para se referir às lideranças envolvidas; é este um processo de substituição que joga com uma atualização dos sentidos em torno de "movimentos sociais" também atravessados por discursos transversos acerca do campo semântico sobre trabalho e sociedade de modo mais geral; assim, o "líder" do movimento social, termo que sustenta um sentido mais ligado ao pertencimento e a assunção em meio ao coletivo passa a ser o "dirigente"; num movimento de troca e substituição, cuja retroação com o sentido dominante é o de conferir naturalidade a uma espécie de "tecnocracia" ou de "profissionalização" inclusive dos movimentos sociais. Em resumo, de um lado, "a equipe da ROTA"; de outro, os "dirigentes dos movimentos sociais".

A seguir continuamos a apontar de que forma as diversas formulações encontradas na imprensa por meio do uso dos significantes há pouco apresentados sustentam gestos de interpretação, cujos efeitos de sentido se dão em torno da apropriação simbólica do real do espaço, senão por meio de crenças imaginárias linearizadas em efeitos de encaixes, pré-construídos e discursos transversos.

Em seguida, elegemos as próximas seqüências discursivas a partir do segundo recorte: trata-se da zona de sentidos instalada com a caracterização de formas narrativas em que se relatam o caráter surpreendente da ação policial. Em meio a este tom de 
ficção, no que se refere à narração cujo eixo articulador se dá pelo uso de um acontecimento surpresa, chama a atenção o uso do termo "invasão".

Vejamos:

SD2 - Título: Invasão do Pinheirinho por PM paulista surpreende governo federal. São Paulo - A operação policial para expulsar os moradores da comunidade Pinheirinho, em São José dos Campos/SP, era desconhecida pelo governo federal, segundo declarou o ministro da Justiça, José Eduardo Cardozo. De acordo com o ministro, a reintegração de posse deflagrada na manhã deste domingo (22), foi "surpreendente". "A informação que tínhamos é que a Justiça Federal tinha suspendido a decisão (de reintegrar a posse do $\underline{\text { terreno) }}$ e que havia um acordo na Justiça de São Paulo para adiar o processo por 15 dias. Hoje ficamos sabendo dessa situação (a invasão policial). (disponível em http://www.tvt.org.br/noticias/invasao-do-pinheirinho-porpm-paulista-surpreende-governo-federal, acesso em 02/05/2013).

O elemento surpresa como domínio de memória sustentado pela ação policial aparece na SD2 em "a reintegração de posse deflagrada na manhã deste domingo (22), foi "surpreendente"". O uso entre aspas de "surpreendente" abre uma polissemia em que convive o sentido de imprevisto e sustenta o sentido dominante do elemento surpresa invariavelmente designado às ações policiais. O campo da significação ligado ao imprevisto é sustentado adiante com o efeito de fechamento ocorrido em "Hoje ficamos sabendo dessa situação (a invasão policial)". Além disto, o efeito de "surpreendente" aberto à polissemia sustenta o sentido de "surpresa" com relação à rapidez linearizada com eficácia.

De volta ao efeito de fechamento, há neste lugar da significação um arremate do sentido dominante da ação policial "surpreendente", em que a indefinição do lugar sintático anafórico de "essa" é disfarçado pelo jogo implícito com a designação de "ação policial" colocada entre parênteses. Essa colocação entre parênteses disfarça o efeito dominante de surpreendente como elemento surpresa do ataque policial àqueles que por esta ação não esperavam. Esse sentido dominante é assegurado também pela retroação com o verbo "deflagrada", cuja zona de sentidos mobiliza "tiro, gatilho".

Este tipo de mobilização do sentido ligado ao flagrante, cuja zona de sentido contribui para alocar a significação dos movimentos sociais no lugar da ação policialesca, como eixo distribuidor de sentidos aparece ainda em:

SD3 - Título: Câmera flagra invasão a padaria próxima ao Pinheirinho Câmeras de segurança flagraram o momento em que pelo menos três pessoas invadiram, saquearam e, logo em seguida, incendiaram uma padaria na madrugada desta segunda-feira (23) próxima à área do Pinheirinho, que neste domingo foi alvo de uma ação de reintegração de posse comandada pela Polícia Militar. (Disponível em http://g1.globo.com/sao-paulo /2012/01/ cameraflagra-invasaopadaria-proxima-pinheirinho.html Acesso em 03/05/2013). 
$\mathrm{Na}$ SD3, aparecem dois usos do verbo "flagrar" para atribuir às ações dos moradores o efeito de elemento surpresa da ação policial, ao descrever de que maneira alguns moradores "invadiram, saquearam e, logo em seguida, incendiaram uma padaria”. Para além desta naturalização do sentido de ataque policial retomando de forma parafrástica a ação policial, porém com mudança da designação, temos a "reintegração de posse" atribuída à polícia, numa inversão especular da ação de tomar posse, outrora atribuída aos moradores.

Ou seja, contraditoriamente, a articulação de uma manobra surpreendente, imprevista da ação policial, não é caracterizada como invasão; por outro lado, quando se trata da significação dos moradores em que se articula "surpresa" a "invasão", temos a migração do significante "surpresa" ou "surpreendente" retroagindo com "invasão". Isto ocorre quando é relatado o retorno dos moradores ao local onde ocorrera a ação policial há um ano, ocasião em que se marca um protesto aos acontecimentos do passado recente do local e de seus antigos moradores.

Essa sustentação de sentido do "elemento surpresa" que passa a significar as ações dos moradores aparece também na SD4.

\begin{abstract}
SD4 - título: Pinheirinho é invadido por uma hora em São José dos Campos - TAUBATÉ - Um grupo de aproximadamente 200 pessoas, entre exmoradores e líderes sindicais, fez uma invasão relâmpago na área desocupada em janeiro deste ano em São José dos Campos, a $81 \mathrm{~km}$ de São Paulo. A ocupação simbólica teve o objetivo de pressionar as atividades para a entrega das casas populares que o governo do Estado prometeu aos ex-moradores (disponível em HTTP://www.estadao.com.br/noticias/cidades,pinheirinho-einvadido-por-uma-hora-em-sao-jose-dos-campos,939107,0.htm; acesso em: 03/05/2012).
\end{abstract}

No trecho "Um grupo de aproximadamente 200 pessoas, entre ex-moradores e líderes sindicais, fez uma invasão relâmpago na área desocupada" destacamos os usos de "invasão relâmpago" retroagindo com os designativos nominais "ex-moradores" e "líderes sindicais".

Temos com isto uma delimitação precisa da ação de "invadir" com rapidez e efeito "surpresa", como havia sido a ação policial inicial. Podemos considerar uma espécie de "ato fundador" da ação policial a partir da qual o processo de significação joga de maneira especular com a sustentação dos sentidos dominantes; pode-nos, assim, "deslocar" o uso do conceito de discurso fundador de Orlandi (2001) para esta análise, na medida em que os discursos sobre a ação policial que mobilizam o campo de sentidos ligados à ação surpresa já estabelecem um lugar de encaixe, em que funciona o discurso transverso (cf. PÊCHEUX, 1993), seja como marca do ponto de retroação 
ligado à descrição da ação dos moradores por meio da zona de sentidos naturalizados por efeito de pré-construído como ação policial, seja pelo disfarce da maneira de esse domínio de memória entrar num jogo especular, em que se inclui a alienação da formação discursiva (FD) "moradores" à FD que a domina ("policiais" e o sentido naturalizado de "ação surpresa").

Faz-se necessário apontar que o lugar de memória deste "elemento surpresa" veiculado pela ação policial se ancora no determinismo bio-político que se fortalece na passagem dos séculos XIX para XX, que, principalmente no espaço urbano demanda do sujeito uma posição, marcada por uma marca no imaginário, marca esta caracterizada pelo valor das atitudes previsíveis.

É a lógica da ciência jurídica, que por influência do empirismo lógico (PÊCHEUX, 1993) defende o pressuposto de que toda e qualquer coisa possa ser identificada (PECHEUX, 1981). Nesta lógica, fortalecem-se a perscrutação pública da conduta do cidadão, como aparece na Criminologia, na Frenologia, na Fisiognomia, enfim no suporte da morfologia anatomo-clínica, que trouxeram ao sujeito o estatuto de objeto das observações científicas; num momento em que o olhar inquisidor sobre o outro reinstalou uma espécie de inquisição, em que a ontologia burguesa da aparente liberdade em saber sobre si disfarça-se no anonimato e na liberdade de escolha (COURTINE \& HAROCHE, 1988).

A docilidade deste homem urbano à perscrutação não aparenta objeção à sociedade da vigilância desde que sejam asseguradas as previsões de cada pequeno ato, para que assim possa ser examinado pelas autoridades jurídicas; somente estas estão autorizadas a aparecerem de súbito.

Devemos considerar ainda que a determinação do político em termos dos papéis sociais (cidadão, agente policial, etc.) em termos de posição-sujeito do discurso se engendra nos dilemas da consolidação da "personalidade democrática" (HAROCHE, 2005) e cuja roupagem imaginária torna-se a dominante. Há, portanto, um dilema entre a harmonia orgânica (traduzida inclusive corporalmente) e suas constantes reviravoltas na deferência e na ilusão de liberdade individual que nos une como cidadãos e em que o urbano sobreposto ao real da cidade por meio de uma mensuração imaginária e identificada com uma roupagem asséptica do "social" (cf. ORLANDI, 2011) tem na posição discursiva do agente policial um controlador das ações imprevistas, um efeito de aparador de arestas da "marginalidade" dispersa e indefinida. 
$\mathrm{Na}$ SD4 continuamos a analisar o funcionamento deste efeito ideológico ligado à autorização da posição sujeito agente policial como eixo organizador dos sentidos sobre “ação surpresa” e "ação policial”.

Há a simulação de uma formação discursiva dominante presente em SD4, quando se afirma que os moradores fizeram uso de "invasão relâmpago". Quer dizer, a memória discursiva em torno de elemento surpresa em uma ação simula entre os "exmoradores e líderes sindicais" o uso legítimo de uma ação por meio da qual foram combatidos, num jogo de espelhamento insidioso porque dissimula o próprio efeito de criminalização dos movimentos sociais atribuindo a estes o sentido de criminalidade, cuja articulação na distribuição dos sentidos aparece no domínio de memória da ação policial.

De modo que se instala a legitimidade do sentido por uma disjunção que disfarça um efeito de causalidade (X porque Y). Vejamos: “ou a ação surpresa é justa porque decorre de ação policial" ou "a ação surpresa deve ser vigiada e criminalizada porque não decorre de ação policial", mesmo que neste efeito resida o disfarce de um giro discursivo de articulação especular, do ponto de vista imaginário.

No terceiro recorte, o domínio de memória da "luta pela terra" lineariza os relatos ao tentar assegurar um sentido sobre o acontecimento. Seguem:

SD5- embora Pinheirinho seja bem menor do que foi Canudos, quanta semelhança existe entre estas duas cidades desventuradas. Canudos foi completamente arrasada pelo Exército, em 1897. As casas foram todas incendiadas e demolidas. A sua população camponesa de aproximadamente quinze mil pessoas foi exterminada no maior massacre já perpetrado ao longo da História do Brasil. (Título: Pinheirinho: uma Canudos em São José dos Campos. HTTP://cspconlutas.org.br/2012/02/pinheirinho-uma-canudos-emsao-jose-dos-campos. Acesso em: 07/05/2013).

Na SD5, "massacre" aparece ao final sem aspas e com o verbo perpetrado, verbo este com carga semântica que se filia ao discurso jurídico ("perpetrar uma ação judicial”, por deslizamento metafórico). Quer dizer, ao dar tom de luta pela semelhança com Canudos, ao mesmo tempo naturalizado efeito da ação jurídica legitimada pelo verbo "perpetrar". Do ponto de vista do domínio de memória do discurso jurídico, se algo foi perpetrado, foi legítimo. Mas o sentido escapa. Notamos que os sites ao retratarem a brutalidade dos acontecimentos são interpelados ideologicamente por conta da intercessão de meandros discursivos que, como tais, apagam os domínios de memória ligados à "luta pela terra". Adiante: 
SD6 - Moradores das proximidades relatavam que os policiais estavam armados e classificaram a ação como um "massacre". (...) Clima de guerra. Na semana passada, jornais de todo o País estamparam fotos impressionantes dos moradores do assentamento, que não se mostravam dispostos a deixar o local. (...) O MPF aponta erros na trajetória dos órgãos oficiais da cidade. Segundo nota, desde 2006 a União procura fazer a regularização fundiária do local, mas encontrou resistência das autoridades do município (Título: Clima de guerra na ocupação Pinheirinho. Moradores ao redor do assentamento Pinheirinho, em São José dos Campos, falam de "massacre" promovido pelos policiais. Por redação Carta Capital - publicado 22/2/2012 10:33, última modificação 22/1/2012, 18:51)

SD7 - Foi uma bofetada na democracia o Jornal Nacional levar ao ar a invenção absurda de que os moradores do Pinheirinho tenham sido obrigados por lideranças a ficarem ali no dia do despejo. Centenas de flagelados depuseram por escrito, assinaram o depoimento e nenhum relatou semelhante coisa. (...) $\mathrm{O}$ povo brasileiro, que em grande parte vive em condições pouco melhores do que aquela em que viviam os flagelados do Pinheirinho antes de virarem moradores de rua, está indefeso diante da sanha do capitalismo selvagem. (Título: JN culpa moradores por tragédia no Pinheirinho. 2/2/2012. HTTP://www.viomundo.com.br/denuncias/eduardo-guimaraes-jornalnacional-culpa-moradores-por-tragedia-do-pinheirinho.html acesso em 7/5/2013)

Nas SD6 e SD7, indiciamos o processo de significação em meio às substituições de "um "massacre"”" por "regularização fundiária do local", na SD6; e, "centenas de flagelados", que, por sua vez, resgata a memória discursiva sobre os "flagelados" do arraial de Canudos, em meio ao qual vem um arregimento de sentidos retroativos ao "flagelo da seca", da migração, etc.

Mas, é na SD7, em "O povo brasileiro, que em grande parte vive em condições pouco melhores do que aquela em que viviam os flagelados do Pinheirinho antes de virarem moradores de rua" que aparecem jogos de sentido opacos sobre a relação com a memória da "luta pela terra". Percebe-se que há uma "voz sem dono" (cf. COURTINE, 1982) em "o povo brasileiro" tal que é assegurado o sentido de que os moradores são "flagelados". Soma-se a isto o domínio do discurso científico em "povo", no caso, no campo semântico da Sociologia.

É possível interpretar então como tal uso incide na cilada imaginária em que a atualização dos domínios de memória disfarça as contradições para fazer crer no sujeito "povo" como origem do próprio discurso (cf. PÊCHEUX, 1993).

Na SD6, temos o embate com a legislação federal acerca do planejamento das cidades no trecho "moradores do assentamento" e "a regulação fundiária do local". A respeito disto, acompanhemos como a Política Nacional de Habitação (Lei 11124/05; fonte: site do Ministério das Cidades. www.cidades.gov.br, acesso em 16/5/2013, p. 18) engloba em seus parâmetros de ação a questão fundiária e territorial. Segue: 
A questão fundiária. A questão fundiária causa impacto tanto no processo de expansão de assentamentos precários como na produção habitacional, e se relaciona de forma direta à política de planejamento territorial e gestão do

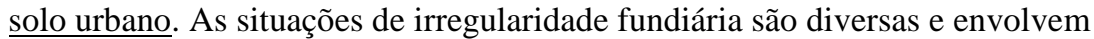
ocupações de terrenos públicos ou privados, loteamentos que não passaram por processos de aprovação por parte dos órgãos públicos, e também estão presentes em boa parte dos assentamentos no País. (negrito no original; grifos nossos)

Essa migração de discursos da zona dos dizeres acerca da luta pela terra e da questão fundiária no campo para uma legislação concernente às cidades, é expressiva de um movimento parafrástico que acoberta a polissemia posto que a complexidade secular da "luta pela terra" em nosso país.

Como se nota, tenta-se apagar a complexidade dos mecanismos discursivos, cujo fundamento é de caráter sócio-histórico, tal que os "assentamentos precários” passam a ser um problema de "gestão do solo urbano", cuja pretensão é administrar os "assentamentos no País", como aparece no arremate de sentido, ao final do enunciado. Os discursos dominantes a respeito de "gestão" se ancoram na matriz de sentidos cujo périplo está na administração científica taylorista.

Deste modo vê-se como, de forma insidiosa, o sujeito é apagado, pois a administração supostamente neutra do espaço urbano deve contornar a "luta pela terra" pela gestão do solo urbano, que, neste caso, parafraseia “assentamento". É um modo, pela incidência do empirismo lógico (cf. PÊCHEUX, 1993) de calar o sujeito.

Trata-se de um efeito de homogeneidade, linearizado como produto reificado do real da história, acobertando acontecimentos de um passado robusto em que temos vários episódios revolucionários, como a Confederação dos Tamoios, Canudos, Contestado, a Revolução Praieira e o massacre de Carajás.

Possibilitando-nos considerar este destaque da legislação como uma das matrizes de sentido sobre a questão fundiária, faz-se necessário considerar também o valor das condições de produção do discurso jornalístico e seu valor ritualístico na consolidação do sentido sobre "ação policial" e "espaço urbano".

É numa ritualização dos dizeres sobre "questão fundiária", "ação policial" que o discurso jornalístico joga com os sentidos sobre a ação policial e assegura sua legitimidade por um mecanismo auto-referencial sobre "espaço urbano". Ou seja, do ponto de vista das condições de produção, é necessário neste momento pontuar ainda que a recorrência às paráfrases atua na constituição da "ação policial" e se filia a um modo de o discurso jornalístico se ritualizar. 
Como resultante, temos como efeito-leitor dominante o lugar a ser ocupado pelo sujeito, já designado pela crença numa confabulação tácita, a ser desvelada pelo discurso jornalístico e em que, por ser baseada em "fatos" disfarça a dispersão, a dimensão das "coisas a saber", e que se incluem os diversos modos dos relatos possíveis de derivarem do "mesmo" acontecimento.

De modo contraditório, a possibilidade de uma tomada de posição discursiva (pelas lacunas interpretáveis do simbólico) divergente do "fato" é apagada pelo lugar imaginário de espectador constituído pelos sentidos dominantes que, não se mostram como disputa, mas de forma linear (MARIANI, 1998).

É assim que a discursivização no discurso jornalístico pela produção em larga escala de materialidades discursivas em que a ritualização narrativa sustenta a ilusão de um lugar no imaginário.

Ao percorrer as inúmeras manchetes sobre os acontecimentos do bairro "Pinheirinho", temos esta marca relevante das condições de produção do discurso jornalístico a partir da qual se articulam disfarces, simulacros e recorrências entre os sentidos de ação policial.

\section{(Des)continuidades do espaço urbano e o real da História: os conflitos sobre o "Direito à propriedade"}

$\mathrm{O}$ apontamento de que em meio às formações discursivas dominantes acima apontadas, há um resto de resistência se fundamenta na insistência do real da luta de classes e sua impossível resolução, de modo que temos um entremeio de dizeres nem abertos, nem fechados, mas que clamam pela continuidade de um embate e movimentação na atribuição de sentidos, possíveis e necessários à promoção de transformações sociais em função da divisão de classes.

A este propósito é inevitável um retorno a Marx e Engels (1998[1845-46]. Os autores explicam que a divisão do trabalho ocorre em função da divisão material e intelectual. Esta última se fundamenta na idéia de uma consciência além das atividades concretas, a delimitação de interesses conflitantes entre o indivíduo isolado, e formas sociais como a família e a comunidade que se acentuam com o predomínio de uma consciência supostamente além das práticas sociais, mas que na verdade "representa realmente algo, sem representar algo real" (p.26). É neste conflito entre individual e coletivo que aparece o Estado como entidade para atender interesses coletivos, 
separado, como se fosse uma "comunidade ilusória" (p.29) negando que a "universalidade é uma forma ilusória da coletividade" (p.30).

Neste caso, chama a atenção a propósito da questão tratada no parágrafo anterior, zonas de sentido em que a naturalização do sentido sobre resolução de contradições sociais é sustentada pela repressão da violenta força coercitiva.

Como vemos no jogo de sentidos sobre as ações policiais no "Pinheirinho", temos na representação dos Aparelhos Repressivos do Estado (cf. ALTHUSSER, 1980), a posição discursiva que naturaliza o gerenciamento prático de interesses (ilusoriamente “coletivo"). De modo que essa posição discursiva alimenta este refreamento ilusório por parte do Estado já presente nas colocações de Marx e Engels (1998/1845-46) quando tratam da mobilização da força produtiva coletiva condicionada pelas formas de lidar com a divisão do trabalho; essas forças são reprimidas porque não se manifestam como articulação individual, mas por força coletiva estranha aos próprios agentes (MARX; ENGELS, 1998[1846/46]. Em suma, há uma força anônima, mas cujo efeito ideológico de evidência deve ser claro do ponto de vista da "ação policial".

Ocorre que nesta força coletiva estranha há um jogo de alienação pautado naquilo que é próprio de como os efeitos de sentido interpelam os indivíduos em sujeito conforme Pêcheux (1993): pelo desconhecimento da causa daquilo que falha na mobilização e na mobilidade das práticas sociais e dos sentidos nela mobilizados.

Isto também tem fundamento no modo como essas forças se articulam no plano da infra-estrutura dos Aparelhos Ideológicos e Repressivos (cf. ALTHUSSER, 1980) em que as representações das representações (ilusórias) da força produtiva (acerca de quem reprime quem) regem formas quase infinitas de espelhamento imaginário entre os sujeitos interpelados pela ideologia; quase, e não totalmente infinitas, por conta do fato de que os determinantes do sujeito - História, inconsciente e língua - estão atravessados pelo político e pela equivocidade de um simbólico fragmentado e disperso, a se reformular (cf. PÊCHEUX, 1993, 1997).

Esta força estranha aos próprios agentes aparece como legado do materialismo histórico-dialético em Pêcheux (1999) quando aponta a relação entre o invisível e o nomeado por meio da interpretação de um acontecimento discursivo, em que numa série discursiva (paráfrase) irrompem marcas significantes, e também, portanto, de dispersão do sujeito a clamar por sentido.

No caso analisado, vemos pulsar em âmbito mais amplo, várias questões dispersas, ao nível do real das "coisas a saber" (cf. PÊCHEUX, 1997) ou mesmo do real 
mítico (cf. PÊCHEUX, 1999), posto que destas sempre se tem apenas formulações ou formas sociais provisórias e ilusoriamente permanentes da condição dos sujeitos falantes. Afinal, resta saber: o que (não) fazer com esta atividade simbólica constitutiva e premente, em que o espaço coletivo é marca social das contradições e interpretação ao mesmo tempo de um enigma coletivo cuja matriz psicanalítica é "por que não nos matarmos uns aos outros"?

Infelizmente, a decifração deste enigma toma a forma de um isolamento dos espaços de troca e debate, fruto da hipertrofia da Personalidade democrática; portanto, há um efeito ideológico de separação entre questões de âmbito coletivo e interesses privados e narcísicos na apropriação privada da questão da habitação como questão pública.

Assim, os dilemas acima apresentados se movimentam em função da “democracia”, apesar da inexorável violência que acoberta seu personalismo. A este respeito Rancière (1995, p. 191) contribui com seu ensaio sobre a maneira pela qual "um pensamento da democracia se ligou a um pensamento do espaço e do território". O filósofo francês denuncia os tentáculos da democracia tocquevilleana norte-americana como excepcional porque nesta, idéias comuns saem de um pensamento comum, como clamor de um espaço virgem para se alocar a liberdade individual total, apagando o pressuposto incontornável de que qualquer espaço é espaço político. Ao destacar esta estranha metáfora utilizada por Tocqueville, Rancière (op.cit. 192) arremata com ironia que se toma:

\footnotetext{
o espaço simbólico americano como espaço da invisibilidade integral e da semelhança infinita. Uma vez mantido o princípio, a igualdade das condições, vê-se tudo. Tudo é identicamente repetição do princípio. A igualdade é uma estrutura do visível: a igual visibilidade do semelhante. A América é o lugar da visibilidade perfeita das condições e é o lugar que se assemelha infinitamente a si mesmo.
}

Mas qual a relação entre esta concepção de espaço e a democracia? Rancière (op. cit., p. 94) afirma ser a realização excepcional da democracia, ou seja, sua realização "na forma de seu desaparecimento". Parafraseamos o autor para sinalizar que do ponto de vista discursivo, é como se fosse possível desdizer o político, ou estabelecer uma marcha de inércia aos discursos que significariam o espaço urbano numa harmonia geométrica pura, sem contradições. Isto porque "a América é a realização exemplar da democracia. E é a realização de uma democracia exemplar que liquida a questão da democracia" (op. cit., p. 194). 
É na esteira também de contradições quase paradoxais que Zoppi-Fontana (2011) aponta furos em slogans acerca do espaço urbano como "bike para todos" em que há o disfarce da invisibilidade dos trabalhadores numa mitificação empírica de união, em que a cidade aparente ser a "mesma" para "todos".

Estas ilusões de homogeneidade e autorreferencialidade, a partir de que se pretende "extirpar" a qualquer custo a diferença radical no/do Outro, remetem ao que Bauman (2003, p. 109) discute acerca da "guetificação", entendida como "paralela e complementar à criminalização da pobreza".

A partir do momento em que o Estado se afasta da regulação das relações de trabalho e o desemprego aumenta em parte por conta das incertezas dos mercados desregulados temos um distanciamento das elites, o que passa pelo esvaziamento dos lugares públicos e coletivos, que, anódinos, garantem vigilância para interesses cada vez mais específicos. Temos assim na guetificação um recurso para conter pobres que não servem nem mesmo para exército de reserva e, menos ainda, para consumidores, tornando-se potencialmente descartáveis uma vez que inúteis.

Temos deste modo o fortalecimento do estigma territorial. Lamentável barbárie traduzida nas seguintes palavras: "a vida no gueto não sedimenta a comunidade. Compartilhar o estigma e a humilhação não faz irmãos os sofredores; antes, alimenta o escárnio, o desprezo e o ódio" (BAUMAN, 2003, p. 109).

\section{Considerações finais}

Desta discussão restam marcas provisórias que desejamos não sejam conclusivas; antes, que insistam na dinâmica de práticas sociais voltadas às ações, considerando-se como ações, os debates sobre as questões aqui tratadas.

Indicamos ainda a necessidade de que o reconhecimento social da alteridade no espaço urbano não seja a hipertrofia da Personalidade democrática e seu disfarce autoritário, mas uma questão, tal como a apresentada no início deste artigo em um dos recortes: "por que não reconhecer a comunidade de Pinheirinho e garantir uma melhor infraestrutura para aquele povo (idem, ibidem)?

\section{Referências}

ALTHUSSER, L. 1980. Ideologia e Aparelhos Ideológicos do Estado. São Paulo/SP: Presença/Martins Fontes. 1980. 
BAUMAN, Z. 2003. "O nível mais baixo: o gueto". In. BAUMAN, Z. Comunidade: a busca por segurança no mundo atual. Rio de Janeiro/RJ: Zahar. 100-112.

COURTINE, J.J. 1982. "Définitions d'orientations théoriques et construction de procédures en analyse du discours ». Philosophies, vol. IX, p.239-265, octobre, 1982.

Carlos-SP: Claraluz editora. 2006. Metamorfoses do discurso político: derivas da fala pública. São

COURTINE, J.J.; HAROCHE, C. 1988. "O Homem perscrutado: semiologia e antropologia política da expressão e da fisionomia do século XVII ao século XIX". Tradução L.R.Romano. In: LANE, S.M.T.. Sujeito e Texto. EDU. São Paulo/SP: 37-60.

HAROCHE, C. 2005. "O comportamento de deferência: do cortesão à personalidade democrática". Tradução de J A. Seixas. In.: História: Questões \& Debates. Curitiba, n.42, p.115-139, ed. da UFPR.

MARIANI, B.S.C. 1998. O PCB e a imprensa: os comunistas no imaginário dos jornais (1922-1989). RJ: Revan, Campinas-SP: Ed da UNICAMP. 1998.

MARX, K.; ENGELS, F. 1998[1845-1846]. A ideologia alemã. Trad. L.C. Costa. SP/SP: Martins Fontes.

ORLANDI, E.P. 1987. A linguagem e seu funcionamento. Campinas/SP: Pontes. 1987.

1996. "Discurso: fato, dado, exterioridade". In.: CASTRO, M.F.P. (org.). O método e o dado no estudo da linguagem. Campinas/SP. Ed. da UNICAMP, p. 209-219.

2001. "Vão surgindo sentidos". In.: ORLANDI, E.P. (org.). Discurso Fundador. $2^{\text {a }}$.ed. Campinas/SP: Pontes. 2001. 7-21.

"A casa e a rua: uma relação política e social". Educ. Real., Porto Alegre, v. 36, n. 3, p. 693-703, set./dez. 2011. Disponível em: http://www.ufrgs.br/edu_realidade. acesso em 3/5/2013.

PÊCHEUX, M. 1981. «L'énoncé: enchâssement, articulation et dé-liaison ». In: Bernard Conein, et alii, eds., Matérialités discursives. Lille: Presses Universitaires de Lille. 1981: 143-148.

Campinas/SP: UNICAMP.

1993. Semântica e Discurso: uma crítica à afirmação do óbvio. Discurso: Estrutura ou acontecimento? Campinas: Pontes, 1997.

Campinas/SP: Pontes. 1999.

"Papel da memória". In. : ACHARD, P. (org.) Papel da memória.

PROST, A. 2002. "Transições e interferências". IN.: P. ARIĖS; G. DUBY (orgs.). História da Vida Privada: da Primeira Guerra aos nossos dias. São Paulo/SP: Cia das Letras. 115-154.

RANCIÈRE, J. 1995. "O continente democrático". In.: J. RANCIÈRE. Políticas da escrita. Rio de Janeiro/RJ: editora 34. 191-201. 
SERRANI, S.M. 1997. "Um método para estudar a discursividade na abordagem de questões socioculturais". In.: SERRANI, S. M. A linguagem na pesquisa sociocultural: um estudo da repetição na discursividade. Campinas/SP: ed. da UNICAMP. 53-71.

TATAGIBA, L; PATERNIANI, S. Z.; TRINDADE, T. A. 2012. "Ocupar, reivindicar, participar: sobre o repertório de ação do movimento de moradia de São Paulo". Revista Opinião Pública, $18(2)$ 399-426. http://www.scielo.br/scielo.php?script=sci_isoref\&pid=S010462762012000200007\&lng $=$ pt\&tlng=pt acesso em 2/5/2013.

VALLADARES, L. 2000. "A gênese da favela carioca. A produção anterior às ciências sociais". Rev. bras. Ci. Soc., São Paulo, v. 15, n. 44, out. 2000. Disponível em $<$ http://www.scielo.br/scielo.php?script=sci_arttext\&pid=S01029092000000300001\&ln $\mathrm{g}=\mathrm{pt \& nrm=iso>}$. acesso em 03 maio 2013. http://dx.doi.org/10.1590/S010269092000000300001.

WISSENBACH, C.C. 1999. "Da escravidão à liberdade: dimensões de uma privacidade possível”. In.: N. Sevcenko (org.). História da Vida Privada no Brasil - vol. 3:República - da Belle Époque à Era doRádio. São Paulo/SP: Companhia das Letras editora. 1999. 49-130.

ZOPPI-FONTANA, M.G. 2011. "a cidade se mexe. Da bicicleta ao cycle chic". Cadernos de Est. Ling., Campinas, v. 53, n. 2, p. 179-196, jul./dez. 2011. 
Para citar essa obra:

PEREIRA, A. C. Havia uma Canudos no "Pinheirinho": em São José dos campos: sentidos sobre ação policial e espaço urbano. In: RUA [online]. 2014, no. 20. Volume 1 - ISSN 1413-2109. Consultada no Portal Labeurb - Revista do Laboratório de Estudos Urbanos do Núcleo de Desenvolvimento da Criatividade www.labeurb.unicamp.br/rua/

Capa: BRASIL DE FATO. 23/01/2012. PM retoma repressão contra moradores do Pinheirinho. Disponível em: www.brasildefato.com.br/node/8657

Laboratório de Estudos Urbanos - LABEURB

Núcleo de Desenvolvimento da Criatividade - NUDECRI

Universidade Estadual de Campinas - UNICAMP

http://www.labeurb.unicamp.br/

Endereço:

LABEURB - LABORATÓRIO DE ESTUDOS URBANOS

UNICAMP/COCEN / NUDECRI

CAIXA POSTAL 6166

Campinas/SP - Brasil

CEP 13083-892

Fone/ Fax: (19) 3521-7900

Contato: http://www.labeurb.unicamp.br/contato 